\title{
Como Seria um Mundo sem Matemática? Hein?! Na tensão narrativa-verdade
}

\section{What Would a World Without Mathematics Look Like?: in narrative truths}

\author{
Sônia Maria Clareto* \\ Margareth A. Sacramento Rotondo ${ }^{* *}$
}

\begin{abstract}
Resumo
A pergunta-provocação Como seria um mundo sem matemática? é o disparador das narrativas e das problematizações que terão lugar nesta escrita. Mas, como uma pergunta dispara narrativas? Como uma pergunta se faz questão? Como narrativas inventam problemas? A aposta é que isso se dá pela e na narrativa que, ao tensionar um evento até seu limite, produz um acontecimento. Um evento que traz salas de aula de cursos de licenciaturas em Matemática e em Pedagogia, causando desassossego no pensar daqueles que ensinarão matemática. É nessa produção que a verdade dá lugar à problematização que interroga a matemática, que vasculha suas entranhas.
\end{abstract}

Palavras-chave: Matemática. Concepções de Matemática. Fabulação. Ficção.

\begin{abstract}
The question "What would a world without math look like?" is the trigger of narratives and problematizations taking place in this writing. But how does a question trigger narratives? How does a question become one? How do narratives invent problems? The bet is that this happens by and in the narrative, which tensions an event to its limits and produces another event. An event that affects classrooms of undergraduate courses in Mathematics and Pedagogy, causing unrest in the thinking of those who teach mathematics. It is in this production that the truth gives place to questioning that interrogates mathematics and scavenges its belongings.
\end{abstract}

Keywords: Mathematics. Conceptions of Mathematics. Confabulation. Fiction

\footnotetext{
* Doutora em Educação Matemática pela Universidade Estadual Paulista (UNESP), Rio Claro, SP, Brasil. Professora Associada da Universidade Federal de Juiz de Fora (UFJF), Juiz de Fora, MG, Brasil. Endereço para correspondência: Rua José Lourenço Kelmer, s/n, Campus Universitário, Bairro São Pedro, CEP: 36036-900, Juiz de Fora, MG, Brasil. E-mail: sclareto@yahoo.com.br.

** Doutora em Educação Matemática pela Universidade Estadual Paulista (UNESP), Rio Claro, SP, Brasil. Professora Adjunto da Universidade Federal de Juiz de Fora (UFJF), Juiz de Fora, MG, Brasil. Endereço para correspondência: Rua José Lourenço Kelmer, s/n, Campus Universitário, Bairro São Pedro, CEP: 36036-900, Juiz de Fora, MG, Brasil. E-mail: margarethrotondo@gmail.com.
} 


\section{Como seria um mundo sem matemática?... ou uma pergunta disparando narrativas...}

As questões são fabricadas, como outra coisa qualquer. Deleuze e Parnet

A turma era pequena. A professora se apresentou - como de costume - logo na primeira aula. Entre os alunos, muitos rostos conhecidos. Todos em busca, sem dúvidas, de um pouco mais. Logo veio a primeira atividade: um soco no estômago. "Como seria um mundo sem matemática?". COMO? Como assim? A primeira ideia foi deixar a cartolina vazia, mas algumas dúvidas surgiram: não existiria nada? Não podíamos fazer isso, alguma coisa iria

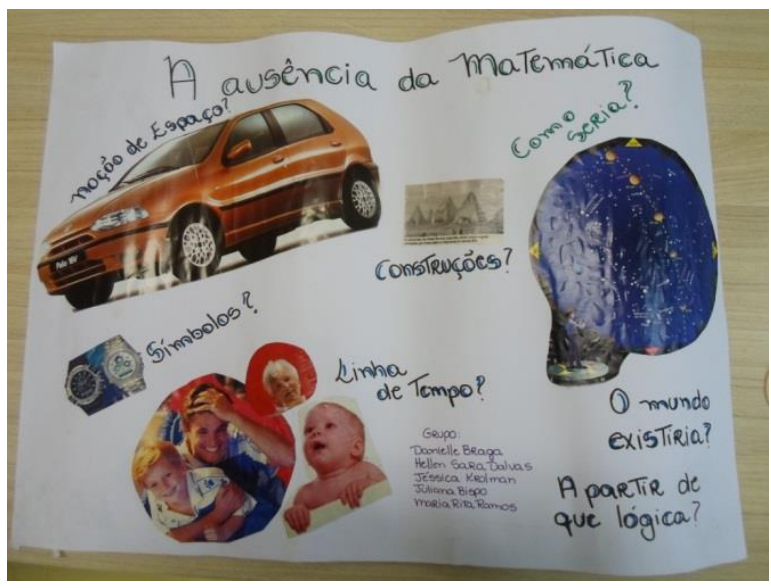
existir. Então, será que existiria a lógica? Ou seria um mundo irracional? Com isso, tivemos a ideia de trabalhar em cima das dúvidas, o mundo seria cheio de perguntas que não possuiriam respostas. Coisas como datas, construções, veículos não existiriam, seriam jogados no lixo.

Um mundo sem matemática seria um mundo irracional? A razão está sempre lado a lado com a matemática? Elas se identificam? Elas se confundem? Se fundem? Razão, que razão? Razões! Razão que vem de lego e logos: ler, discursar e o próprio discurso. Lego e logos tornam-se ratio, reor e ratus: medir, pesar, calcular, pensar, julgar ${ }^{i}$. Pronto: aí se dá o encontro: uma razão e uma matemática. Então, um mundo sem matemática seria um mundo sem razão, um mundo ilógico. Isso significaria que seria sem conhecimento? Sem pensamento? É possível pensar sem a razão? Sem a lógica? Ora, se razão é o poder de julgar de forma correta e discernir entre verdadeiro e falso ${ }^{i i}$, seria possível sobreviver sem esse poder? Quer dizer, já se nasce com uma certa porção - ou uma porção certa - de razão, como uma faculdade natural? Se assim for, deve haver uma ciência geral que explique tudo o que se pode investigar acerca da ordem e da medida, uma ciência universal que se aplique a tudo e não a algo particularmente, uma matemática universal ${ }^{i i i}$. 
Quando me vi diante da pergunta estampada no quadro branco, escrito em azul - como seria um mundo sem matemática? - fiquei atônita! Como assim, um mundo sem matemática? Hein? Não, um mundo assim seria impossível! Puxa vida, não haveria nada! O homem viveria em estado primitivo... Pera lá: não, acho que nem existiria o homem, nem mesmo a natureza. A Terra não é redonda? É isso, não existiria a Terra. A órbita dos planetas em torno do sol não é elíptica? Então não existiriam os planetas com suas órbitas. Nada. Um nada. Uma folha em branco. Só isso...

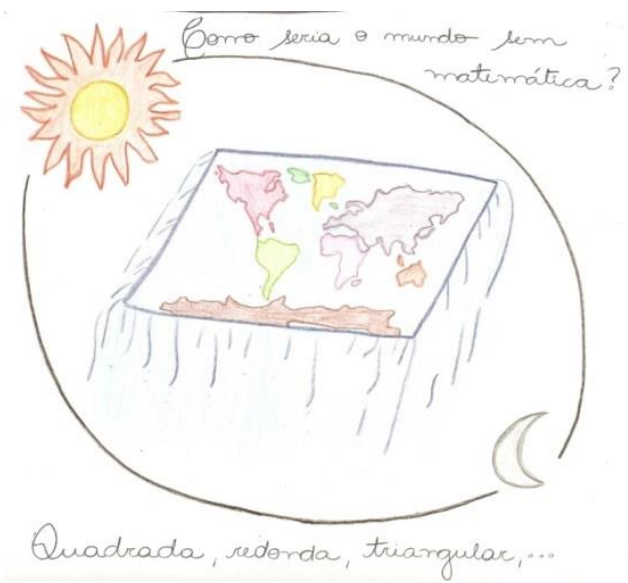

Então, a matemática rege o universo, como leis a serem seguidas? Ah, então todo o universo é um grande livro que continuamente se abre perante nossos olhos, que não se pode compreender antes de entender a língua e conhecer os caracteres com os quais está escrito. Seria isso? Mas veja bem, o universo está escrito em língua matemática, os caracteres são triângulos, circunferências e outras figuras geométricas, sem cujos meios é impossível entender humanamente as palavras; sem eles nós vagamos perdidos dentro de um escuro labirinto ${ }^{i v}$. Acho que um mundo sem matemática seria um escuro labirinto. Escuro. Labirinto. Uma folha preta? Preta, sim, mas não uma folha plana. Uma folha amassada tridimensionalizada, caotizada, labirintizada. Sem ordem, sem lógica, sem

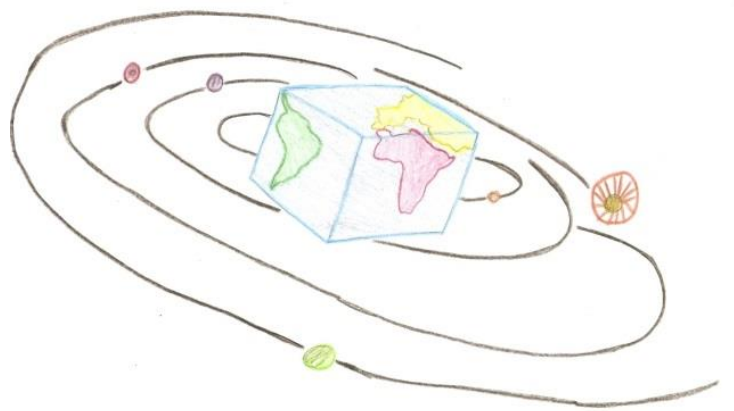
racionalidade, sem inteligibilidade. Uma folha anoturnada, tornada noturna.

Como seria possível um mundo sem matemática? Por exemplo, as abelhas constroem a sua “casa" para que possa haver um maior aproveitamento possível do espaço, não é mesmo? Mas, será que elas sabem que estão utilizando a matemática? Será que é necessário saber explicar para poder utilizar? Mas como chegaram àquela conclusão sem saber matemática? Só sei que foi extremamente difícil destruir a fortaleza chamada de matemática. Fortaleza essa 
que, ao longo do caminho, foi se transformando em pó. E foi sendo (re)construída, de modo diferente.

Um mundo com matemática seria uma fortaleza? A matemática dá segurança porque ela é exata. Os conceitos são inequívocos e não se pode duvidar. É??? É claro que sim, os conceitos matemáticos compreendem uma lógica que se distancia das sensações, do corpo. O corpo, com suas sensações, pode nos enganar. A lógica, ao contrário, nunca nos engana. Pois $a$ lógica é um sistema formal de proposições e operações que são tomadas como verdades a priori. Seus enunciados não derivam da experiência, que pode nos enganar. Mas, as proposições e regras lógicas são formais e gerais, portanto elas são vistas como verdades universais. Desta maneira, o sistema lógico pressupõe a existência de casos e objetos idênticos. Assim, o que está no fundamento da lógica é a crença na identidade; esta, por sua vez, pressupõe a convicção de que existe um mundo absoluto, supra-sensível, verdadeirov . Matematizando o mundo, constituímos o mundo verdadeiro; ou ainda, o mundo é verdadeiro, pois que é matematizado. Um mundo de verdades. Verdades matemáticas. Verdades dadas pela lógica. Lógica? Fé! É que nossa fé nas coisas é a condição primeira para a fé na lógica ${ }^{v i}$.

Na primeira aula foi proposta uma atividade em grupos para discussão do tema: "Como seria

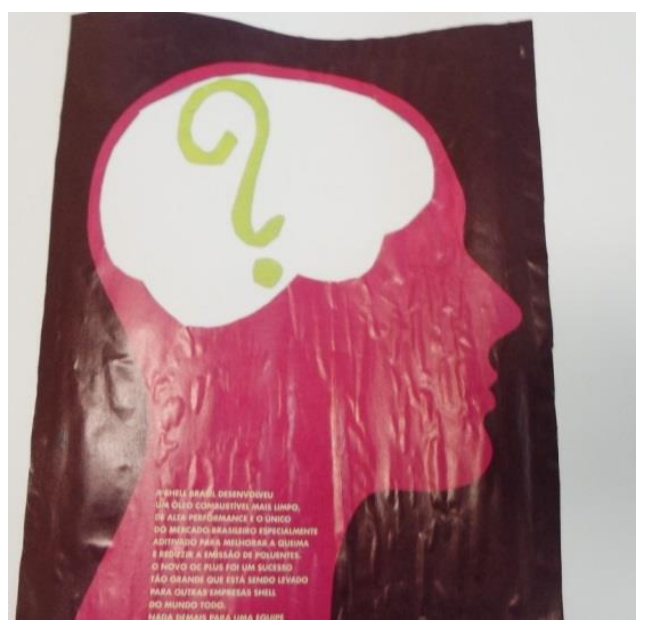
um mundo sem matemática?". Na elaboração do cartaz eu e os integrantes do meu grupo começamos a imaginar como seria nosso mundo sem a matemática e não como seria um mundo qualquer sem a matemática. Então, a partir do que existe em nosso mundo começamos a ver o que precisou da matemática para existir. Acabamos concluindo, provisoriamente, que até cada pensamento, por menor que seja, tem a matemática por trás. Sem matemática, sem pensamento. Só que depois desta conclusão nos deparamos com uma figura, uma flor desenhada a partir de pontos, que ligando um ao outro formou a flor. Tal figura fez com que chegássemos a outra conclusão que, mais tarde, foi posta em discussão em sala de aula, para que todos pensassem. A questão era a seguinte: será que a matemática existe no mundo desde 
seu início, ou seja, a matemática preexiste ao ser humano ou será que ela é uma produção humana? A partir dessa discussão fiquei pensando que mesmo sem o conceito de matemática, desde os homens da caverna, a matemática sempre esteve presente. Talvez, mesmo se não intitulássemos tal prática como matemática, ela continuaria existindo. Talvez até mesmo não como a matemática que temos hoje, mas no meu ponto de vista seria impossível sobreviver sem algum tipo de racionalidade.

Como desconsiderar o que já há, o que já é e já está no mundo? Como desconectar-se deste mundo e colocar-se a fabular um mundo sem matemática? Como tirar a matemática de cena? Ou tirar uma matemática de uma cena? Como fabular um mundo sem matemática? Como? Será que isso seria uma produção humana? Como fazer de algo tão importante como a matemática, um inexistente? Bem, um grilo é mais importante que um navio. Isso do ponto de vista do grilo $^{\text {vii }}$. Pensar como grilo, grilar.

Pois é, mas eu fiquei muito confuso com a atividade do mundo sem matemática... Para mim, a matemática dá segurança, a certeza de que eu posso chegar a uma verdade, sem erro, precisa e exata. Por isso eu escolhi fazer o curso de Matemática! Aí, diante da atividade, fiquei sem chão: como eu poderia pensar que a matemática é uma produção humana e não uma descoberta de verdades que constituem o mundo? Como posso pensar isso? Então, o mundo não está desde sempre criado com toda a exatidão matemática? Foi muito duro pensar isso tudo. Eu não queria mais pensar.

Como se dá a inteligibilidade do mundo? E a inteligência do homem? A base é a matemática. $\mathrm{O}$ isomorfismo que existe entre o mundo ou os objetos e a racionalidade humana. Fortaleza, certeza, segurança... Um mundo completamente inteligível para um ser inteligente. $\mathrm{O}$ conhecimento seria fruto dessa relação entre um ser inteligente e um objeto inteligível. A ciência - e, é claro, a matemática, como rainha da ciência - produziria uma inteligibilidade completa do mundo. Verdade. Pronto: inteligibilidade total: nada de escuridão labiríntica.

Aquela atividade em que tínhamos que pensar num mundo sem matemática, para mim foi um sofrimento. Escolhi fazer o curso de Matemática porque era uma coisa exata. Sempre tive bons resultados em matemática, quando estava na escola. Então, me deparar com aquela 
questão, parecia totalmente sem sentido. Queria que o tempo parasse: eu não queria pensar naquilo. Quando saí da aula, queria esquecer, mas não conseguia. Aquilo me deixou uma marca, cheguei em casa e falei para o meu pai: “Pai, eu até hoje vivi uma mentira!".

Será que falta sempre um pouco para se perder a razão ${ }^{\text {viii }}$ ? Como entender a perfeição do imperfeito $^{i x}$ ? Com um corpo todo que experencia atormentado no desassossego do pensar. Torna-se movimento em pele, em língua. Pele sensível à produção de marcas. Marcas: estados inéditos que se produzem num corpo, a partir das composições que vai vivendo. Estados inéditos que instauram uma abertura para a criação de um novo corpo, o que significa que as marcas são sempre gênese de um devir ${ }^{x}$.Língua que perde o sentido das dicotomias mentira-verdade e perfeição-imperfeito. Língua torcida. Corpo dobrado.

Veja bem, estou no terceiro período do curso de Pedagogia e nunca gostei muito de matemática... Para ser sincera mesmo, a matemática sempre foi um problema para mim na escola. Agora vou ter que encarar mais duas disciplinas de matemática: eu serei professora de matemática! E vou ensinar aquilo que não dei conta de aprender! Dá até um frio na barriga. Puxa!! E já no primeiro dia de aula da disciplina de matemática na Pedagogia, me deparo com uma pergunta: como seria um mundo sem matemática? Eu e minhas colegas achamos graça. Uma de nós disse baixinho: "O mundo seria cor de rosa!”. Sorrimos todos.

Um desejo de praticar os rosas? Nem clarear, nem noturnar: rosear. Um delírio do substantivo tornado verbo. E o verbo tem que pegar em delírio ${ }^{x i}$. Como seria um mundo rosa, roseado? Rosa - cor-de-rosa, cor de rosa, rosáceo ou rosado - é uma cor intermediária entre magenta e vermelho, sendo assim uma cor quente. No intermediário, no vivido, no entre-quente do viver. Existem, porém, muitas máscaras diferentes desta cor $^{\text {xii }}$. Que máscaras teria um mundo rosa, um mundo sem matemática? Que máscaras? Uma máscara rosácea que traz a infância e a feminilidade, que traz o in-fante: o indizível? Ou os muitos dizíveis de uma indizência? Que mundo com o Rosa que diz das e nas margens e poeta o viver? Que mundo com poesia? Poesia que é voz de poeta, que é voz de fazer nascimentos ${ }^{\text {xiii }}$ ? Um mundo assim? Nesse mundo-rosa ou no mundo-do-Rosa cabe matemática? Uma matemática poetada? Uma matemática-rosa? $O$ mundo é mágico ${ }^{x i v}$... e a matemática é magia? 
Quando eu vi aquela atividade com a questão - como seria um mundo sem matemática? - me veio uma alegria!!! Nunca me dei bem com a matemática da escola. Acabei optando pelo curso de Pedagogia para ter menos disciplinas com matemática, com cálculos, com fórmulas... Pensei que num mundo sem matemática eu ia ser bem mais feliz. É, mas como seria um mundo sem matemática? Ela está em tudo, ela é muito importante para nossa vida, em tudo que fazemos. Desde a hora em que acordamos ela está presente: para contar o tempo, para fazermos compras, até na hora que tomamos um ônibus. Pensa bem?! Como imaginar nossa vida sem as tecnologias que contribuem tanto para nosso conforto, saúde e bem estar? É, apesar de não gostar muito da matemática, ela é importante. Fui eu quem não dei conta dela na escola. Mas, na vida eu lido bem com dinheiro, com uns cálculos mentais... Essas coisas do dia a dia, sabe?

A matemática seria uma entidade, ou seja, aquilo que constitui a essência de alguma coisa ${ }^{x v}$ ? Essência de um mundo-verdadeiro, regido logicamente. Em várias de suas concepções, a matemática é tomada como a essência da racionalidade universal, totalizadora, que traz consigo a verdade única. Como lidar com a matemática que está na escola, se ela se aproxima dessa entidade? Às vezes essa lida é difícil e guetos são produzidos. São produzidos a nobreza de Estado, os funcionários do Estado e muitos dispensáveis ${ }^{\text {xvi }}$. Uma matemática acontece na escola. Ela se aproxima da matemática do matemático, que tem seus monstros ${ }^{x v i i}$ e seu território, o Jardim do Matemático ${ }^{\text {xviii }}$, acessível à nobreza de Estado. Já os funcionários são úteis, repetem a matemática do matemático sem a produção do conhecimento matemático, sem se incomodar, sem desassossego, atendendo às demandas de um certo modo de estar no mundo, de um certo mundo. Já os dispensáveis, esses recebem a identificação de fracassados. Uma des-identidade ${ }^{x i x}$. Há um monstro que habita a fronteira do Jardim do Matemático e o lado de lá, um fora do Jardim. Deixar o monstro escapar é não dar conta da matemática da escola. E é neste deixar-fugir é que se funda um processo de seleção e exclusão exercido pela matemática $^{x x}$. Como, a matemática não é tão importante? Aí parece acontecer uma descontinuidade entre as concepções de matemática do senso comum e aquela que dá suporte à matemática ensinada nas escolas ${ }^{x x i}$. 


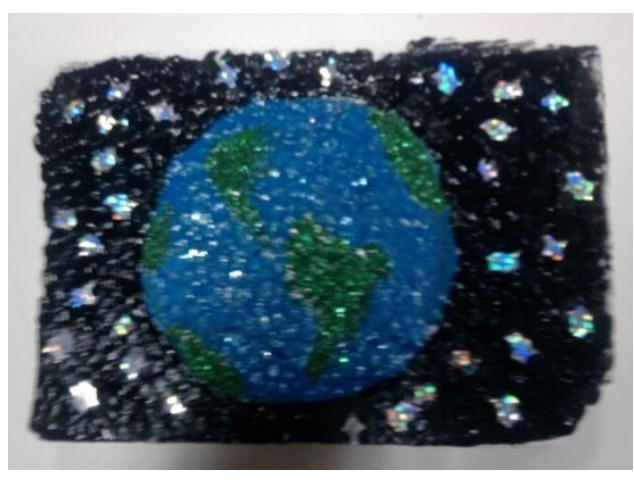

Meu grupo fez uma maquete de um mundo sem matemática que envolvia um planeta com palitos de

picolé
fincados,
representan
do uma
cerca. $\mathrm{Na}$

apresentação para a turma, explicamos que a cerca mostrava que um mundo sem matemática fica muito limitado, pois perderíamos várias

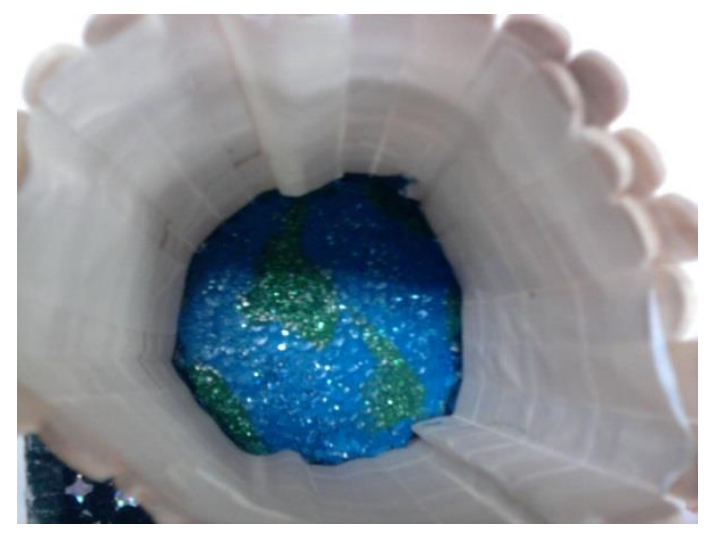
possibilidades de resoluções de problemas. Pensamos na matemática nesse sentido, no de facilitar a vida em sociedade e, até mesmo, na questão de desenvolvimento social, cultural e econômico.

Um mundo cercado? Um mundo limitado? Matemática como um facilitador do desenvolvimento social, cultural e econômico. Mas, o que significa isso? A matemática existiria antes do ser humano se estabelecer no mundo? Então, só seria possível uma sociedade, depois que a matemática - ou seria: uma matemática - se estabelecesse sobre o mundo? Só assim seria possível uma sociedade? A matemática, então, seria prévia ao mundo? Só assim uma cultura se estabeleceria? Então, a matemática estaria no mundo antes do humano? Só assim o humano se tornaria econômico? Uma cerca estabelecida, uma dependência lógica: se matemática, então homem. Como?

Quando eu e meus colegas começamos a pensar no grupo parecia que não conseguiríamos fazer nada: como seria um mundo sem matemática? Mas, chegamos a confeccionar um cartaz no qual dizíamos que, num mundo sem matemática, estávamos no vazio. Até porque partimos do pressuposto de que ela - a matemática - já existia e, por isso, não conseguimos nos desapegar dela. Isso ocorreu também na apresentação de outros grupos. Foram apresentadas diversas visões e possibilidades de um mundo sem matemática, mas também, em todas elas, não havia seres humanos. Será porque associamos a matemática aos seres humanos? 
Desapegar, descolar, desgrudar o corpo... Fazer-se em corpo-movente-pensamento. Permitir, a experiência, o vazio, o nada, outras lógicas, outras racionalidades. Pôr-se em experiência, ser em experiência. Permitir a des-razão ou as dez-razões, o des-humano ou os dez-humanos. Des-matematizar ou dez-matematizar, o pensar. Pensar enquanto produção de problemas, enquanto invenção. Enfraquecer a ligação razão-humano. Permitir as dez-lógicas. Permitir ao corpo-movimento no viver. Permitir ao corpo a invenção de sua humanidade experienciada, a invenção de mundos. Aprender a viver num mundo que não fornece um fundamento preestabelecido, num mundo que inventamos ao viver, lidando com a diferença que nos atinge $^{x x i i}$. Insistir em coisas que não querem mais ser vistas por pessoas razoávies ${ }^{x x i i i} \ldots$.

$\mathrm{Na}$ discussão de "como seria um mundo sem matemática?", rolou um exemplo bem interessante que foi: uma pessoa precisa alcançar algo em uma árvore e, através da comparação entre o tamanho dos galhos, chega à conclusão de qual galho seria o maior ou o menor para, assim, escolher o que melhor atenderia sua necessidade. Neste momento, a matemática, pura e simples, já existia. Os povos já a utilizavam para contar os objetos e animais, desenhando na parede, por exemplo. Essa matemática, como construção necessária, já havia sido e foi, ao longo dos anos, sendo produzida por outras pessoas. A matemática não estava presente no universo para ser descoberta. Ela é invenção.

Descobrir seria invenção? Des-cobrir: tirar a coberta. Invenção: ação do inventar. Des-cobrir: então há o algo sob a coberta, algo que existe e pode ser reconhecido. Invenção: um algo se faz em produção, num não reconhecimento, com produção de problemas. Como descobrir aproxima-se do inventar? Como o descobrir contamina o inventar? Quando a razão, a racionalidade, a lógica apoderam-se dos corpos para assim, e só assim, se permitirem humanos. Humanidade engolida pela racionalidade. Língua levada a territórios do reconhecimento, da submissão, da despotencialização do viver. Se descubro, não invento, reconheço.

Depois de toda a discussão que se deu junto à temática de um mundo se matemática, começo a me questionar se enquanto estou tomando como uma verdade a matemática como preexistente, se isso não pode ser uma influência direta do meu convívio na escola, com as metodologias utilizadas pelas professoras ou com as fórmulas que, supostamente, eram 
ensinadas e que para nós, estudantes, era algo tão fácil de fazer. Isso porque estas fórmulas vinham como uma receita de bolo, explicando como fazer e você nunca questionava. Não questionava porque fazia isso todo dia, já que era mais cômodo repetir os mesmos gestos todos os dias.

Uma matemática escolar produzindo modos de existir, silenciosamente. Produzindo modos de estar no mundo atrelado a um pensamento dogmático. Despotencializando a experiência do viver, do produzir matemática. Como uma questão se faz problema? Como "um mundo sem matemática” se produz problema? Quando um corpo se implica num viver-pensar.

\section{Narrativas em narrativa... ou o avesso do avesso...}

De onde estava, ela podia avistar um tapete, tão irregular e de colorido tão vário que dir-se-ia terem sido muitas as mãos a manejar as agulhas. A disparidade de tecidos, cores, linhas e direções, conferia uma profusão de motivos, díspares por vezes, mas belos em sua inteireza. Na trama, contudo, ela não conseguira descobrir nenhum nó. Possível? O que ali marcava vínculos? Impusera, então, a si uma tarefa: perscrutar as sendas daquela tessitura. E como, ali, ninguém mais houvesse, se aproximou com cuidado e,

brusquidão insuspeita nela e na sala, virou o tapete do avesso.

Nilma Lacerda

Diante da questão fabricada - como seria um mundo sem matemática? - narrativas são instauradas. Como narrativas se instauram?

Diante da questão fabricada - como seria um mundo sem matemática? - mundos são inventados. Como mundos se inventam?

Mas, qual o interesse de se inventar um mundo sem matemática? É um bom recurso didático para ensinar concepções de matemática. Gera muitas discussões e polêmicas e, com isso, a aprendizagem das concepções de matemática - como preexistente ao ser humano e como criação humana - são abordadas de um modo muito interessante! Porém, esses mundos criados não podem ser levados a sério, não é mesmo? Afinal de contas, tais mundos não existem de verdade, eles são só invenções, são ficções, não são válidos como conhecimento. 
A realidade material na qual vivemos nos coloca diante de um mundo com matemática, com muita matemática.

Que mundo com matemática é esse? Um mundo com segurança. Um mundo com exatidão. Um mundo confiável, pois que mensurável no qual a existência se dá de modo lógico, através de regularidades, de implicações diretas entre a causa e o efeito, sem contradições. Ora, é que procuramos a "verdade": um mundo que não se contradiz, não se engana, não muda, um mundo verdadeiro... ${ }^{x i v}$. Mas a busca pela "verdade" pretende atender a uma necessidade que temos de segurança, na medida em que "o mundo que não se contradiz” é o mundo do permanente, do estável, portanto, do que é antes de mais nada idêntico a si mesmo ${ }^{x x v}$. Veja, a matemática é a ciência das identidades. Ela opera nas e com as identidades. Baseia-se no princípio da identidade que tem como pano de fundo a "ilusão de ótica" de que existem coisas $_{\text {idênticas }}{ }^{x v i}$. A matemática se fundamenta, então, em uma crença, a crença na identidade? Uma matemática substancializada: ela existe "em si e por si”, independente do mundo, da vida, da existência. Ela simplesmente existe e sua essência é aquilo que se mantém permanente no fluxo da mudança ${ }^{x x v i i}$. Uma matemática isolada, independente, idêntica a si $m e s m a^{x x v i i i}$. Uma metafísica. Uma crença. Uma ficção.

Um mundo com matemática, mas que matemática? Uma matemática que se coloca como modelo de verdade. Então, desde sempre já dada. Modelo. Verdade. Verdade? Um batalhão móvel de metáforas, metonímias, antropomorfismos, enfim, uma soma de relações humanas, que foram enfatizadas poética e retoricamente, transpostas, enfeitadas, e que, após longo uso, parecem a um povo sólidas, canônicas e obrigatórias: as verdades são ilusões, das quais se esqueceu que o são, metáforas que se tornaram gastas e sem força sensível, moedas que perderam sua efígie e agora só entram em consideração como metal, não mais como moedas ${ }^{\mathrm{xxix}}$. A matemática que, após longo uso, parece a um povo sólida, canônica e obrigatória seria também uma ilusão?

Mas, qual o interesse de se inventar um mundo sem matemática? Quando se cria um mundo, ele não passa a existir? Quer dizer: ao fazer um exercício de criar um mundo, entra-se em uma experiência - com racionalidades outras, com sentires outros. Entra-se em uma narrativa que cria mundos. Uma aposta: é na e pela narrativa que mundos são inventados. Fabulando, 
mundos vão sendo criados quando o elo entre vida e ficção é estabelecido. Pensar e existir coengendrados: existência outra para mundo outro inventado, fabulado. A fabulação tem uma potência falsificadora que é antes de tudo uma potência criadora de mundo, mundos habitáveis e vivíveis ${ }^{x x x}$. Então, não seria a ciência, ela mesma, uma fabulação?

Essa invenção possibilita dar a ver, experimentar e sentir a potência falsificadora e fabuladora da ciência que se tem em conta, por diversos motivos, como verdade... É a ciência produzindo aquilo que quer - seu projeto epistemológico - e dando a ver aquilo que ela nega - sua condição existencial...

Mas, qual o interesse de se inventar um mundo sem matemática? Para dar a pensar. O que já é muito. Mais importante do que o pensamento é "aquilo que faz pensar",xxxi . Dar a pensar no sentido de apoderar o pensar de um desassossego. No sentido de tirar os significados postos, de abalar as vidas acomodadas em certos modos de existir em suas representações de mundos. Desabituar. Fazer com que o corpo pense e que a inteligência venha a funcionar por último. Como, pensar com o corpo? Sim, um pensar que desestabilize as semelhanças, as identidades, as analogias, que se desaproprie da lógica. Nada de modelo de verdade.

Que mundo sem matemática é esse? Um mundo em desabituação. Uma desabituação na e com a matemática. Então, esse não seria um mundo com matemática? Um mundo com matemática! Mas um mundo-com-matemática-desabituada. Como uma matemática se constitui como desabituada? Um pensamento matemático que opera fora da imagem dogmática de pensamento $^{\text {xxxii }}$; um pensamento sem pressupostos, mas ainda assim, matemático. Sem pressuposto porque abre mão dos modelos de verdade; abre mão de pensar com as semelhanças, com as identidades, com as analogias dadas desde sempre para se lançar à aventura de uma invenção, uma invenção matemática.

Inventar um mundo sem matemática... Uma fabulação. A produção de uma ficção. Ora, mas a ficção não se opõe ao real? A ficção se opõe ao modelo de verdade. Quer dizer: o que está em jogo não é a veracidade ou não da ficção: a ciência é tão verdadeira quanto qualquer outra ficção. Não se trata disso. O que está em jogo é que a ciência, enquanto ficção - criadora de mundos - tem uma potência falsificadora. Puxa, o que é afirmado não é a veracidade da 
ficção, mas sua realidade falsificadora ${ }^{x x x i i i}$ !! Isso coloca em questão os modelos de verdade, as metanarrativas, a metafísica. Isso afirma as invenções, as narrativas, a produção na imanência.

\section{A narrativa da narrativa... ou da constituição de uma política de narratividade...}

Tudo é real, por que tudo é inventado Guimarães Rosa

Um pós-escrito, com uma escrita. Um pós que vem junto, que é um aquém e um além da própria escrita. É que a inteligência vem sempre depois ${ }^{x x x i v}$. Só que nas escritas acadêmicas, em geral, ela vem antes: iluminando, abrindo caminhos de inteligibilidade. Esta escrita se coloca no lugar de desabituar esse modo de escrita acadêmica. Por opção epistemológica? Sim. Por opção teórica? Sim. Por opção metodológica? Também. Mas especialmente, por uma opção política, que desabitua o pensar, desabitua a escrita. É que a inteligência vem sempre depois; ela é boa quando vem depois ${ }^{x x x v}$. Depois.

Depois, num pós-escrito, a escrita se mostra em sua condição política: uma ação, um exercício, uma prática: uma política de narratividade. É que a inteligência vem sempre depois; ela é boa quando vem depois, só é boa quando vem depois ${ }^{x x v i}$. Depois.

A fabulação tomou conta da escrita, rompendo com o passado e se colocou em processo de invenção. Não uma escrita presa a uma imagem-memória do vivido em sala de aula de formação de professores que ensinam matemática, que pretende reproduzir o passado, o vivido em sua pureza, mas uma escrita que se faz junto a uma imagem-fábula, que é uma imagem constituída por uma dobra da ficção. É o próprio presente que se abre ao futuro deixando entrever os estados de mudança que o atravessam ${ }^{x x x v i i}$. É que a fabulação é cisão e não coexistência. Ela cinde, ela rompe, ela violenta o passado ${ }^{\text {xxxviii }}$.

Uma política de narratividade que se coloca aberta à narrativa, em movimento de narração. Sem pré-tensões de verdade, a narratividade coloca-se em problematização, se pergunta pelas implicações da vontade de verdade instituída pela moral $^{x x x i x}$. Com tensões à emergência da 
invenção de verdades, a narratividade vaza não-ditos, torce os ditos e atravessa um vivido, se implicando com e no existir...

Quando cheguei em sala de aula, já atrasado, olhei para o a quadro branco e lá estava uma pergunta escrita em azul: Como seria um mundo sem matemática?

Hein?!?!

\section{Referências}

BARBOSA, W. do V. Razão Complexa. In HÜHNER, L. M. (Org.). Razões, Rio de Janeiro: Uapê, 1994, p. 17-43.

BARROS, M. Poesia completa. São Paulo: Leya, 2010.

BUENO, S. Minidicionário da língua portuguesa. São Paulo: FTD, 2000.

CAMMAROTA, Giovani. Fabulações e modelos ou como políticas cognitivas operam em educação matemática. 2013. 154 f. Dissertação (Mestrado em Educação). (Faculdade de Educação). Universidade Federal de Juiz de Fora, Juiz de Fora, 2013.

CAPITAL INICIAL. Do outro lado da rua. In: Saturno. Rio de Janeiro: Universal, 2012. 1CD, faixa 3.

CLARETO, S.; ANASTACIO, M. Q. A. Concepções de matemática e suas incidências na Educação Matemática. In: Simave/Faced/Caed. Boletim Pedagógico de Matemática. Juiz de Fora: UFJF, 2001.

DELEUZE, G. Proust e os signos. 2. ed. Tradução A.C. Piquet e R. Machado. Rio de Janeiro: Forense Universitária, 2006a.

DELUZE, G. Diferença e Repetição. 2. ed. revis. e atual. Tradução L. Orlandi; R. Machado. São Paulo: Graal, 2006b.

DESCARTES, R. Discurso do Método. Trad. Eurico Corvisieri. SP: Nova Cultural, 1637/1999. (Os Pensadores).

DESCARTES, R. Regras para a Direção do Espírito. Trad. João Gama, Textos Filosóficos. Lisboa: Edições 70, 1989.

GALILEU, G. O Ensaiador. Trad. Helda Barraco. SP: Nova Cultura, 1623/1999. (Os Pensadores).

GUimarães ROSA, J. Discurso de Posse Na ABL. 1967. Disponível em:

http://www.academia.org.br/abl/cgi/cgilua.exe/sys/start.htm?infoid=685\&sid=96. Acesso em: 01 mai 2012.

KASTRUP, V. A invenção de si e do mundo: uma introdução do tempo e do coletivo no estudo da cognição. Campinas: Papirus, 1999. 
LINS, R. C. Matemática, monstros, significados e educação matemática. In: BICUDO, M.A.V.; BORBA, M.C. (Org.). Educação Matemática: pesquisa em movimento. São Paulo: Cortez, 2004.

NIETZSCHE, F. A vontade de potência. São Paulo: Editora Escala, s/d.

NIETZSCHE, F. Sobre Verdade e Mentira no Sentido Extra-moral. In: Nietzsche: obras incompletas. Trad. Rubens R. Torres Filho. SP: Abril Cultural, 1873/1999, p. 53-60. (Os Pensadores).

NIETZSCHE, F. Nietzsche: obras incompletas. Trad. Rubens R. Torres Filho. SP: Abril Cultural, 1873/1999. (Os Pensadores).

PIMENTEL, M. R. Fabulação: a memória do futuro. 2010. 152 f. Tese (Doutorado em Letras) Programa de Pós-graduação em Letras. Pontifícia Universidade Católica do Rio de Janeiro (PUC-RJ), Rio de Janeiro. 2010.

ROLNIK, S. Pensamento, corpo e devir: uma perspectiva ético/estético/política no trabalho acadêmico. Cadernos de Subjetividade: Núcleo de Estudos e Pesquisas da Subjetividade do Programa de Estudos Pós-Graduados em Psicologia Clínica da PUCSP, São Paulo, v. 1, n. 2, p. 241 51, fev./set. 1993.

SKOVSMOSE, O. Educação Crítica: incerteza, matemática, responsabilidade. São Paulo: Cortez, 2007.

Wikipédia. Cor-de-Rosa. Disponível em http://pt.wikipedia.org/wiki/Cor-de-rosa. Acessado em 20/07/2013.

ZATERKA, Luciana. Nietzsche: a "verdade" como ficção. In: MARTON, Scarlett; SILVA JÚNIOR, Ivo da Cadernos Nietzsche 1, São Paulo: UNIFESP. 1996. p. 83-92.

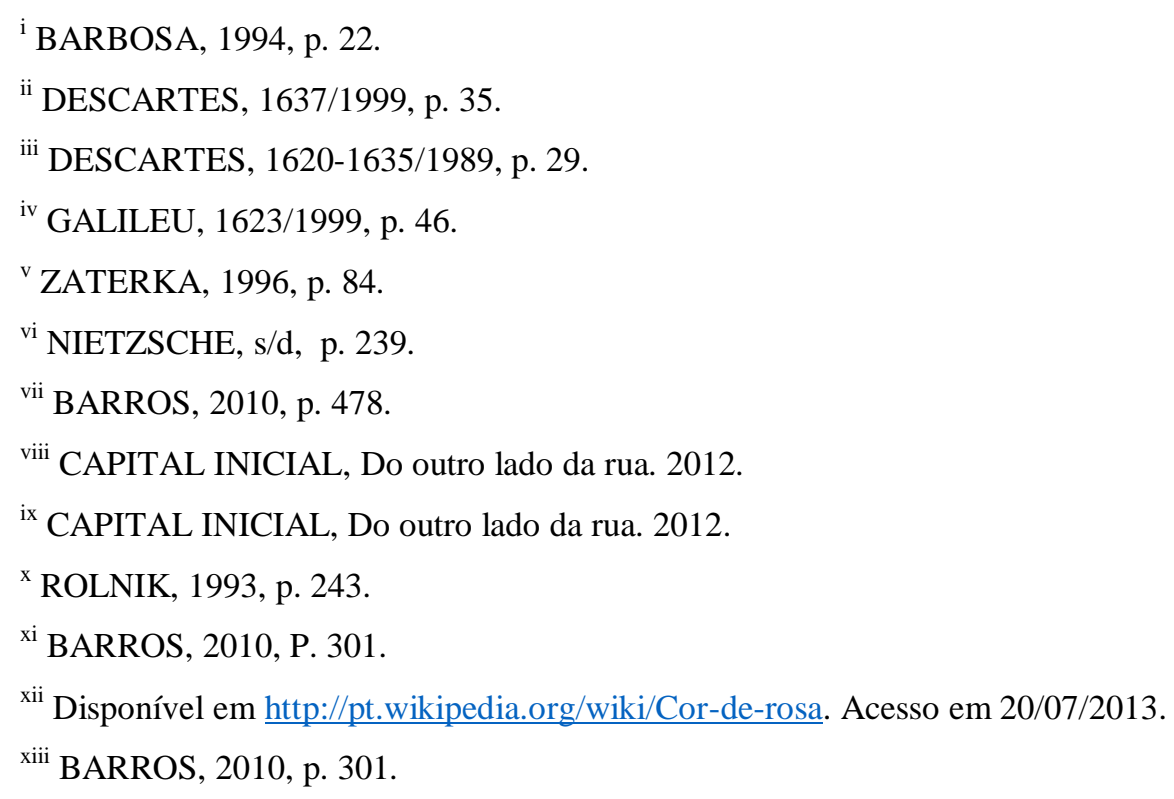


xiv GUIMARÃES ROSA, 1967, s/p.

${ }^{\mathrm{xv}}$ BUENO, 2000, p 298.

${ }^{\text {xvi }}$ SKOVSMOSE, 2007.

xvii LINS, 2004.

xviii LINS, 2004.

${ }^{\text {xix }}$ LINS, 2004, p. 103.

${ }^{\mathrm{xx}}$ LINS, 2004, p. 106.

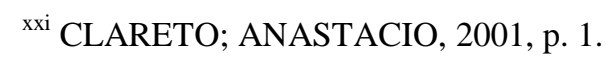

xxii KASTRUP, 1999, p. 194.

xxiii BARROS, 2010, p. 302.

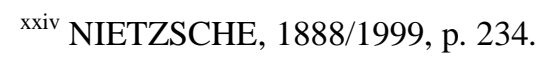

${ }^{\mathrm{xxv}}$ ZATERKA, 1996, p. 85.

xxvi ZATERKA, 1996, p. 84.

xxvii ZATERKA, 1996, p. 85.

xxviii ZATERKA, 1996, p. 85.

xxix NIETZSCHE, 1873/1999, p. 57.

${ }^{\mathrm{xxx}}$ PIMENTEL, 2010, p. 134.

xxxi DELEUZE, 2006a, p .29.

xxxii DELEUZE, $2006 \mathrm{~b}$.

xxxiii PIMENTEL, 2010, p. 134.

${ }^{\text {xxiv }}$ DELEUZE, 2006a.

${ }^{\text {xxxv }}$ DELEUZE, 2006a, p. 95.

xxxvi DELEUZE, 2006a, p. 95.

xxxvii PIMENTEL, 2010, p. 140.

xxxviii PIMENTEL, 2010, p. 137.

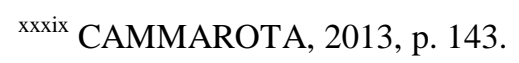

